Categorie Italiane. Studi di poetica e di letteratura [Categorias Italianas. Estudos de poética e de literatura]. Giorgio Agamben (Bari: Laterza, 2010, pp. 200.)

\title{
UM FILÓSOFO NOS MEANDROS DA LITERATURA: AGAMBEN E AS CATEGORIAS ITALIANAS
}

Giacomo Leopardi, em algumas passagens do seu Zibaldone di Pensieri (1817-1832), reflete sobre a relação entre o poeta e o filósofo. Em um trecho de 1821, o autor de "L'Infinito" afirma que "quem não tem ou nunca teve imaginação, sentimento, capacidade de entusiasmo, heroísmo, de ilusóes vivas e grandes, de fortes e várias paixôes, quem não conhece o imenso sistema do belo, quem não lê ou não ouve, ou nunca leu ou ouviu os poetas, não pode absolutamente ser um grande, verdadeiro e perfeito filósofo [...]”.

Esse não parece ser o caso de Giorgio Agamben, que, no recém-publicado Categorie Italiane. Studi di poetica e di letteratura [Categorias italianas. Estudos de poética e de literatura], demonstra possuir uma profunda afinidade com temas literários, ser um grande conhecedor de obras, escritores, críticos e ter sensibilidade para discutir sobre o "belo". Aliás, em Nudità (2009) Agamben diz que "uma obra crítica ou filosófica, que não está em algum modo em relação essencial com a criação, está condenada a ficar no vazio, assim como uma obra de arte ou poesia, que não contém em si uma exigência crítica, está destinada ao esquecimento".

Foi com Italo Calvino e Claudio Rugafiori que Agamben, entre 1974 e 1976, pensou em um projeto de revista para a editora Einaudi. A única coisa acordada entre os três, como o próprio Agamben conta, é que uma das seções da revista deveria se dedicar ao esboço conceitual das assim chamadas "categorias italianas", visando, portanto, a abranger, através de uma série de pares dicotômicos, as características fundamentais da tradição cultural italiana, em particular a literária. $\mathrm{O}$ projeto acabou não dando certo, mas Agamben, continuando fiel aos princípios teóricos que o tinham norteado, publica, em 1996, pela editora Marsilio, uma primeira versão de Categorie italiane, onde ele dá justamente forma, embora parcial e provisória (enquanto parte de uma tentativa de sistematização mais ampla, ainda por cumprir), à tensão dialética entre aquelas "estruturas categoriais" cuja definição, na realidade, 
transcende - apesar de os textos analisados serem quase todos italianos, com a única exceção dos sirventeses do provençal Arnaut Daniel - o seu específico e explícito âmbito de referência nacional. De qualquer maneira, como o livro estava esgotado há muito tempo, no início de 2010, felizmente, a editora Laterza colocou no mercado editorial italiano uma edição nova e atualizada, que, conforme declara o autor na "Avvertenza alla presente edizione" [Advertência à presente edição], é um livro "substancialmente novo", devido ao "número e à importância dos textos acrescentados" (p. v), como, de resto, se pode verificar ao final do livro, na "Nota ai testi" [Nota aos textos], contendo as informações precisas de onde cada ensaio foi publicado ou apresentado, qual é inédito, qual não é. Além disso, na qualidade de uma autêntica mais-valia exegética, esta nova edição conta ainda com um belo posfácio, de sabor tipicamente agambeniano ("Profanare il dispositivo"/Profanar o dispositivo), assinado por Andrea Cortellessa, um dos mais brilhantes representantes da nouvelle vague da crítica italiana.

No entanto, na impossibilidade de dar conta, em conjunto, de uma coleção de ensaios tão instigante, talvez valha a pena destacarmos alguns deles, em que esse método analítico por meio de categorias antitéticas se revela hermeneuticamente mais produtivo, a partir, por exemplo, daquela oposição tragédia/comédia sobre a qual se constrói o primeiro "exercício de leitura" do volume, tendo como objeto nada menos que o maior clássico da literatura italiana: a Divina Comédia, de Dante Alighieri. De fato, no texto intitulado justamente "Comedia", Agamben retoma a velha questão do título da obra, que foi bastante subestimada pela crítica e que, a seu ver, ainda hoje mereceria estudos mais aprofundados, pois Dante, com toda a sua erudição, não teria decerto escolhido este nome, que indica um gênero literário específico, sem algum critério bem fundamentado. É nesse sentido que o autor de O que é contemporâneo? se debruça sobre o "problema" da aparente contraditoriedade de uma titulação cômica para um projeto poético que, na esteira de outras obras dantescas, parecia nascer sob o signo do trágico (pense-se, por exemplo, no De Vulgari Eloquentia) e cuja explicação não pode se contentar, então, com o lugar-comum crítico da oposição entre tragédia e comédia do ponto de vista da matéria, isto é, da diferente articulação interna do conteúdo, distinguindo entre o início "próspero" e o fim "horrível" (típico da tragédia) e seu contrário (o início horrível e o fim próspero, tão característico da 
comédia). Com efeito, essas categorias de trágico e cômico, que o próprio Dante, na sua célebre carta a Cangrande della Scala, tinha contribuído a cristalizar em uma oposição conteudística condizente essencialmente com os ditames das poéticas medievais, se redefinem agora não só no quadro temático da inocência e da culpa, vistas da perspectiva do subiectum (para o qual tragédia e comédia não passam de modalidades literárias de seu percurso de condenação ou salvação individual), mas também no contexto de outro dualismo irredutível, aquele entre natureza e pessoa, ou seja, cindindo a culpa natural da culpa pessoal e transformando, assim, o conflito trágico entre inocência pessoal e culpa natural na "conciliação cômica da inocência natural e da culpa pessoal". Considerado por esse ângulo, o título da Divina Commedia - no centro da qual está a justificativa do culpado ao invés da punição trágica do justo - não se limita a ser "perfeitamente coerente", como se torna também revelador da íntima tendência anti-trágica da cultura italiana que Dante vai passar para a posteridade.

Mas se o diálogo de Dante com a poesia provençal constitui o imediato elo de ligação unindo "Comedia" ao texto sucessivo, "Corn: dall'anatomia alla poetica" ["Corn: da anatomia à poética”], no qual Agamben relê alegoricamente o debate diacrônico em torno daquela controversa palavra epônima (corn) usada pelo trovador Arnaut Daniel - que, diferentemente da sua interpretação literal, se torna, antes, o equivalente semântico de rima não encadeada (convertendo, dessa forma, o suposto tema obsceno do sirventês num problema métrico) -, é sobretudo esse curto-circuito vertiginoso entre filologia e filosofia que marca uma das principais linhas de continuidade ao longo dos textos. Basta ver, por exemplo, os dois ensaios logo a seguir, "Il sogno della lingua" [O sonho da língua] e "Pascoli e il pensiero della voce" ["Pascoli e o pensamento da voz"], onde o eixo filológico da dicotomia entre língua viva e língua morta acaba sendo ressemantizado no horizonte filosófico de uma experiência de linguagem que se situa para além das línguas, naquele não lugar entre o que foi (língua morta/voz) e o que ainda não é (língua viva/significado), delimitando assim uma dimensão negativa aberta tanto para o ser quanto para o abismo da nada. Não é por acaso que, no primeiro elemento desse díptico ensaístico, vale dizer em "Il sogno della lingua", ao tratar de um incunábulo impresso em Veneza em 1499, Hypnerotomachia Poliphili, e do estranhamento que o leitor tem ao ler tal obra, pois não 
sabe em qual língua está lendo ("se em latim ou em vulgar ou em um terceiro idioma”, p. 46), Agamben fala de "um unicum monstruoso" decorrente da fago-citação lexical do latim por parte da estrutura frásica do italiano, embora essa contaminação linguística encontre seu pleno sentido só na reflexão metalinguística que ela contém acerca do bilinguismo (não apenas quatrocentista) enquanto condição inerente à qualquer palavra humana (daí o sonho, justamente, com uma "língua desconhecida e novíssima" que está por detrás da história de Polia e Polifilo e no qual o leitor vai ouvir ressoar a lição benjaminiana da "reine Sprache"...).

Sempre a relação entre língua morta e língua viva continua sendo o âmago da questão em "Pascoli e il pensiero della voce", conquanto, desta vez, a língua morta não seja mais o latim como a língua da poesia em geral, na qual cabem também aquelas célebres glossolalias e onomatopeias tão ao gosto do lírico decadente italiano. Só que estas, longe de serem a expressão de uma linguagem pré-gramatical - conforme a classificação do crítico italiano Contini - representam, pelo contrário, a gramaticalização daquela voz da natureza, cuja morte está inscrita mesmo nas letras das palavras, como uma intenção de significado a se realizar, porém, unicamente na linguagem articulada. Contudo, retomando algumas observações que estavam já presentes no seu ensaio de 1982, Il linguaggio e la morte [A linguagem e a morte], Agamben não identifica aqui a Voz com a mera phoné, mas sim com aquela vontade de significação permitindo a passagem para o logos, de modo que a letra dos poemas pascolianos se torna afinal, na leitura dele, uma experiência de morte: morte da voz que, ao se inscrever nos signos linguísticos, morre como puro som (onomatopeia) e morte da língua que, ao se reduzir a som, marca a sua saída da dimensão semântica (glossolalia). Mas se, "a poesia é experiência da letra" - conclui o filósofo - pode existir uma experiência da palavra (como também da poesia e do pensamento) que vai para além da letra?

A esta pergunta, Agamben responde indiretamente em "Il dettato della poesia" [O ditado da poesia], onde aborda a relação entre vida e poesia, ou melhor, aquela oposição biografia/fábula, a qual pressupõe, justamente, a relação mais problemática entre vida e palavra. Nessa análise, o autor passa pela tradição teológica, pela literatura dos séculos XIII e XIV até chegar ao século XX, com a poesia de Antonio Delfini, que tenta recompor aquela fractura entre realidade e literatura, antes que ela, mutatis mutandis, se pro- 
ponha de novo, na poesia de Caproni ("Disappropriata maniera" [Maneira desapropriada]) sob a forma da divaricação entre estilo e maneira. A mesma lógica de análise se dá no capítulo 7 , no qual Agamben fala da poesia de Andrea Zanzotto e da sua peculiar e indissolúvel reflexão sobre língua e prática poética. Já em "Il torso orfico della poesia" [Anatomia órfica da poesia], temos a discussão sobre o caráter elegíaco da poesia, principalmente a do século XX. Segundo ele, esta pode ser definida através da contaminação entre hino e elegia. No último texto do livro, intitulado "La fine del poema" [O final do poema], Agamben trata, como o título do capítulo sugere, do final do poema, pois os estudos sobre o assunto são praticamente inexistentes. Aqui, o filósofo, na tentativa de elaborar uma teoria própria, fala da relação entre poesia e verso, rima e metro, som e sentido, a ponto de afirmar que "se o verso se define através da possibilidade do enjambement, disso segue que o último verso da poesia não é um verso" (p. 141). O resultado disso será "uma verdadeira e própria crise de vers, em que está em jogo a sua própria consistência” (p. 141).

Esse grande interesse de Agamben pela poesia em seus mais variados aspectos vai, guardadas as devidas proporções, na mesma direção proposta por Leopardi, pois a poesia e a filosofia estão no mesmo nível, andam lado a lado e são, nas palavras de Leopardi “o ápice do humano espírito[...]".

Embora os capítulos 8, 10 e 11 não tratem de poesia, discutem temas afins e que podem se relacionar aos assuntos mostrados acima. No capítulo 8 entra em cena a relação entre literatura e política, através da análise do léxico (teológico/político) do escritor Giorgio Manganelli. No capítulo 10, Agamben discute a paródia, através da análise de textos não tão clássicos como Lisola di Arturo ( $A$ ilha de Arturo. Tradução e apresentação de Loredana de Stauber Caprara. São Paulo: Berlendis \& Vertecchia, 2005.), de Elsa Morante, em que o gênero paródia é o protagonista do livro. Por fim, no capítulo 11 o autor trata da relação entre literatura e filosofia, especialmente da presença de Spinoza em textos de Elsa Morante.

Um das características recorrentes dos ensaios do livro é a forma "adorniana" de coordenação dos elementos com que Agamben constrói os seus escritos, que aqui podem ser lidos autonomamente. Também o conjunto de textos parece formar um pequeno "sistema" das categorias literárias italianas, que serão úteis para refletir sobre a literatura italiana, mas também sobre outras literatu- 
ras, porque Agamben utiliza a forma comparada de análise. Aliás, o ex-professor de filosofia da Universidade de Veneza sabe que a literatura pode ser vista como um eterno "corso-ricorso" viconiano, simplesmente porque "qualquer coisa acaba para sempre e qualquer coisa começa, e aquilo que começa, começa apenas naquilo que acaba" (p. 95).

Esperemos que essa obra de Agamben, autor muito traduzido entre nós, ganhe em breve uma edição brasileira. Como costuma ocorrer com os textos dele, Categorie Italiane agradará tanto os estudiosos de literatura, quanto os que não estão satisfeitos com o especialismo por vezes um pouco asfíxico da crítica literária e gostam de novos horizontes epistemológicos, conscientes de que - como dizia Barthes - "passar da leitura à crítica é mudar de desejo, é desejar não mais a obra, mas sua própria linguagem”.

Andréia Guerini (Universidade Federal de Santa Catarina) Roberto Mulinacci (Università degli Studi di Bologna) 